TITLE:

\title{
Dimethyl carbonate as potential reactant in non-catalytic biodiesel production by supercritical method
}

\section{$\operatorname{AUTHOR}(\mathrm{S}):$}

Ilham, Zul; Saka, Shiro

\section{CITATION:}

Ilham, Zul ... [et al]. Dimethyl carbonate as potential reactant in non-catalytic biodiesel production by supercritical method. Bioresource Technology 2009, 100(5): 1793-1796

\section{ISSUE DATE:}

2009-03

URL:

http://hdl.handle.net/2433/87775

\section{RIGHT:}

c 2009 Elsevier Ltd All rights reserved.; This is not the published version. Please cite only the published version.; この論文は出版社版でありませ ん。引用の際には出版社版をご確認ご利用ください。 


\section{Dimethyl Carbonate as Potential Reactant in Non-Catalytic Biodiesel Production by Supercritical Method}

Zul Ilham and Shiro Saka*

Department of Socio-Environmental Energy Science, Graduate School of Energy Science, Kyoto University, Yoshida-honmachi, Sakyo-ku, Kyoto 606-8501, Japan

*Corresponding author:

Shiro Saka

Department of Socio-Environmental Energy Science, Graduate School of Energy Science, Kyoto University, Yoshida-honmachi, Sakyo-ku, Kyoto 606-8501, Japan

Tel : +81-75-753-4738

Fax: +81-75-753-4738

E-mail address: saka@energy.kyoto-u.ac.jp 


\begin{abstract}
In this study, the non-catalytic supercritical method has been studied in utilizing dimethyl carbonate. It was demonstrated that, the supercritical dimethyl carbonate process without any catalysts applied, converted triglycerides to fatty acid methyl esters with glycerol carbonate and citramalic acid as by-products, while free fatty acids were converted to fatty acid methyl esters with glyoxal. After 12 min of reaction at $350{ }^{\circ} \mathrm{C} / 20 \mathrm{MPa}$, rapeseed oil treated with supercritical dimethyl carbonate reached $94 \%(w / w)$ yield of fatty acid methyl ester. The by-products from this process which are glycerol carbonate and citramalic acid are much higher in value than glycerol produced by the conventional process. In addition, the yield of the fatty acid methyl esters as biodiesel was almost at par with supercritical methanol method. Therefore, supercritical dimethyl carbonate process can be a good candidate as an alternative biodiesel production process.
\end{abstract}

Keywords: biodiesel; fatty acid methyl ester; dimethyl carbonate; supercritical process; glycerol carbonate. 


\section{Introduction}

In recent times, the world has been confronted with an energy crisis due to depletion of fossil resources and increased environmental problems, particularly global warming (Sheehan et al., 1998). Such a situation has led to the increase of research for an alternative energy such as biofuels from sustainable biomass resources. Among biofuels, biodiesel exhibits fuel properties compatible to those of petroleum-based diesel, and is commercialized for use in existing motor vehicles.

Currently, the alkali-catalyzed method is the most common and commercially available process for biodiesel production. However, water and free fatty acids (FFA) in oils/fats result in reducing the catalytic activity, thus, decreasing the yield and complicating the purification process. This has prevented the use of waste oils, high in free fatty acids and water for its production (Mittelbach and Remschmidt, 2004; Tomasevic and Marinkovic, 2003).

In order to overcome this problem, our laboratory has developed a catalyst-free supercritical methanol method: one-step method (called "Saka Process") and two-step method (called "Saka and Dadan Process") which has been proven to produce biodiesel with advantages of simpler process, higher yield and easier purification (Kusdiana and Saka, 2004; Saka and Kusdiana, 2001).

In addition, Isayama and Saka (2007) developed an alternative new process with other potential reactants such as methyl formate and methyl acetate of carboxylate esters to produce fatty acid methyl esters (biodiesel) with triacin from oils and fats without producing glycerol. Since triacin has very similar fuel properties as biodiesel, a mixture of fatty acid methyl esters and triacin was demonstrated for use as biodiesel. On this line 
of study, dimethyl carbonate rather than methanol was selected as a reactant for noncatalytic supercritical treatment and investigated for its potential for biodiesel production.

This paper presents the potential of supercritical dimethyl carbonate for the production of biodiesel. A special attention was focused on the superiority of this process in producing by-products which are much higher in value than the glycerol produced in conventional methanol process with a similar yield of fatty acid methyl ester.

\section{Methods}

Vegetable oil used in this study was rapeseed oil, purchased from Nacalai Tesque Inc. In addition, dimethyl carbonate, methanol, various fatty acid methyl esters and fatty acids such as palmitic, stearic, oleic, linoleic, linolenic acids and glyoxal were also obtained from Nacalai Tesque Inc. as standards. Citramalic acid was, on the other hand, obtained from Aldrich, while glycerol carbonate was obtained from Tokyo Chemical Industry. Details on physical and thermodynamic properties of dimethly carbonate are shown in Table 1.

The supercritical biomass conversion system developed previously in our laboratory was the one employed in this work (Saka and Kusdiana, 2001). A $5 \mathrm{ml}$ reaction vessel made of Inconel-625 was used in this system as batch-type in which the pressure and temperature were monitored in a real time, operating up to $200 \mathrm{MPa}$ and $550{ }^{\circ} \mathrm{C}$, respectively. For the transesterification, the reaction vessel was charged with a given amount of rapeseed oil $(1.08 \mathrm{ml})$ and liquid dimethyl carbonate $(3.92 \mathrm{ml})$ with a molar ratio of 1:42. Then, the reaction vessel was immersed quickly into the molten tin bath to have a reaction temperature up to $350{ }^{\circ} \mathrm{C}$, and kept for a set time interval for the 
supercritical treatments of dimethyl carbonate (Tc: $274.9^{\circ} \mathrm{C} / \mathrm{Pc}: 4.63 \mathrm{MPa}$ ) from 3 to 15 min. The reaction vessel was then moved into a water bath to stop the reaction.

For the esterification, oleic acid $(1.06 \mathrm{ml})$ was mixed with the liquid dimethyl carbonate $(3.94 \mathrm{ml})$ in a molar ratio of $1: 14$, and the mixture was treated at $300{ }^{\circ} \mathrm{C} / 9$ MPa by the batch-type reaction vessel.

After the treated rapeseed oil was allowed to settle, it was evaporated at $90{ }^{\circ} \mathrm{C}$ for 20 min to remove the existing dimethyl carbonate. Consequently, the remaining was settled to be separated into the upper and lower portions. The upper portion was then analyzed for its composition by using high performance liquid chromatography (HPLC) (Shimadzu, LC-10AT) which consists of the column (Cadenza CD-C18) and refractive index detector (Shimadzu, RID-10A) operated at $40{ }^{\circ} \mathrm{C}$ with $1.0 \mathrm{ml} / \mathrm{min}$ flow-rate of methanol as a carrier solvent. The sample injection volume was $10 \mu \mathrm{l}$ and the peak identification was made by comparing the retention time between the sample and the standard compounds.

On the other hand, the lower portion was analyzed with gel permeation chromatography (GPC) (Shimadzu LC-10A) consisting of an ultraviolet light detector (Shimadzu, SPD-10Avp, $\lambda=205 \mathrm{~nm}$ ), a refractive index detector (Shimadzu, RID-10A) and Asahipak GF310-HQ column operated at $40{ }^{\circ} \mathrm{C}$ with $1.0 \mathrm{ml} / \mathrm{min}$ flow-rate of acetone as a carrier solvent.

For comparison, biodiesel was produced from rapeseed oil by the one-step supercritical methanol method (Tc: $239{ }^{\circ} \mathrm{C} / \mathrm{Pc}$ : $\left.8.09 \mathrm{MPa}\right)$, developed by Saka and Kusdiana (2001) with the same parameters as described above. The resultant fatty acid methyl esters were analyzed by HPLC in a similar manner. 


\section{Results and discussion}

\subsection{Transesterification of the rapeseed oil in supercritical dimethyl carbonate}

Dimethyl carbonate is a unique molecule having versatile reactivity, nontoxic and biodegradable produced by an environmentally benign process (Tundo, 2001; Wang et al., 2006; Tundo and Selva, 2002).

Under the ambient pressure and temperature of $90^{\circ} \mathrm{C}$, triglycerides can react with liquid dimethyl carbonate with a catalyst, sodium methoxide, to produce a mixture of fatty acid methyl esters with fatty acid cyclic glycerol carbonate ester (FAGC), glycerol carbonate and glycerol dicarbonate as by-product and intermediates after $5 \mathrm{~h}$ of reaction (Fabbri et al., 2007). The reaction is such that it is time-consuming and due to the usage of catalyst, it requires separation and purification process.

In this study, however, triglycerides of the rapeseed oil were treated with dimethyl carbonate in its supercritical condition without applying any catalyst. As a result, the reaction mixture was separated into the upper and lower portions after evaporation of dimethyl carbonate.

Fig. 1 shows gel permeation chromatography (GPC) chromatograms for the upper portion of rapeseed oil as treated in supercritical dimethyl carbonate at $350{ }^{\circ} \mathrm{C} / 20 \mathrm{MPa}$ for various reaction times. It is shown clearly in the chromatogram at 3 min reaction time that the mixture can be separated to four peaks. Peaks observed at $6.8 \mathrm{~min}, 7.2 \mathrm{~min}, 7.4$ min and 8.0 min retention times were identified to be triglyceride (TG), methyl carbonate diglyceride (MCDG), dimethyl carbonate monoglyceride (DMCMG) and fatty acid methyl ester (FAME), respectively, by comparing with authentic compounds. 
Fatty acid methyl esters produced from rapeseed oil are known to consist of methyl palmitate $\left(\mathrm{C}_{16,0}\right)$, methyl stearate $\left(\mathrm{C}_{18-0}\right)$, methyl oleate $\left(\mathrm{C}_{18-1}\right)$, methyl linoleate $\left(\mathrm{C}_{18-2}\right)$ and methyl linolenate $\left(\mathrm{C}_{18-3}\right)$, in which the former number represents the one of the carbons in the hydrocarbon chain, while the latter the number of the double bond. These fatty acid methyl esters appeared at retention times between 7 and 11 min in HPLC analysis, as supercritical dimethyl carbonate was used without any catalyst.

However, high temperature $\left(350^{\circ} \mathrm{C}\right)$ and high pressure $(20 \mathrm{MPa})$ of the supercritical fluid employed in this process may affect the thermal stability of the fatty acid methyl esters (FAME) and this explains the slightly lower yield of FAME after a 15 min treatment. Fatty acid methyl esters including poly-unsaturated ones were partially decomposed at high temperatures to reduce the yield, in addition to the isomerization of the cis-type to trans-type (Imahara et al., 2008).

Fig. 2 shows the GPC analysis of the lower portion. By comparing it with the authentic compounds of glycerol carbonate and citramalic acid, the lower portion contained these compounds. Based on these lines of evidence, it may be concluded that the transesterification reaction of the rapeseed oil in the supercritical dimethyl carbonate proceeds without any catalyst through the three stepwise reactions.

Triglycerides (TG) react with dimethyl carbonate to produce methyl carbonate diglycerides (MCDG), and then methyl carbonate diglycerides react to produce dimethyl carbonate monoglycerides (DMCMG). Finally, dimethyl carbonate monoglycerides react with dimethyl carbonate to give yield of fatty acid methyl ester (FAME) with glycerol carbonate and citramalic acid as by products. At each reaction step, one molecule of fatty acid methyl ester is produced for each molecule of dimethyl carbonate consumed. 
In supercritical fluid science, an excessive amount of dimethyl carbonate was used in this reaction to shift the equilibrium to the right side in favor of the product. The main difference of this reaction compared to the supercritical methanol process is that glycerol carbonate (GC) and citramalic acid (CA) exist in the lower part as by-products after the supercritical dimethyl carbonate treatment, apart from only glycerol in the supercritical methanol process. The produced citramalic acid may be expected to work as an acid catalyst for the transesterification reaction.

\subsection{Esterification of fatty acids in supercritical dimethyl carbonate}

In addition to transesterification of triglycerides, esterification reaction of fatty acids was essential in supercritical dimethyl carbonate to prove its potential as a reactant. Therefore, its reactivity was studied without using any catalysts to convert fatty acids into their corresponding methyl esters. Rapeseed oil consists of various fatty acids but the major one is oleic acid constituting $60 \%$ of all (Warabi et al., 2004). Therefore, oleic acid was used as fatty acid in this study. From the HPLC analysis, it can be observed that a highly selective reaction definitely resulted, since the reaction products were only the corresponding methyl esters. As depicted in Fig. 3, the yield is also comparable to the transesterification system. From these observations, dimethyl carbonate clearly has a potential as a reactant in the supercritical process to convert fatty acids into biodiesel. The esterification of free fatty acid in supercritical dimethyl carbonate was assumed to proceed in a reaction where the fatty acid reacts with dimethyl carbonate in producing fatty acid methyl ester, glyoxal and water. 
Glyoxal which is ethanediel formed in the esterification of free fatty acid is highly miscible in water, typically formed when oils and fats are subjected to high temperature (OECD SIDS, 2000). In addition, it may further react with water to be converted into glycolic acid (Kiyoura and Kogure, 1997), which can work as an acid catalyst in the reaction system.

\subsection{Yield of FAME from rapeseed oil treated with supercritical dimethyl carbonate}

Fig. 3 shows a comparison in the yield of fatty acid methyl ester (FAME) from rapeseed oil treated with supercritical dimethyl carbonate $\left(350^{\circ} \mathrm{C} / 20 \mathrm{MPa}\right)$ and FAME from supercritical methanol $\left(350{ }^{\circ} \mathrm{C} / 43 \mathrm{MPa}\right)$. It can be seen that the yield of FAME treated with supercritical dimethyl carbonate is lower than that with supercritical methanol. However, after $12 \mathrm{~min}$ of reaction, the yield from supercritical dimethyl carbonate reach $94 \%$ which is almost at par with that from supercritical methanol process.

These studies were done in a batch reaction vessel so that the pressure in reaction was not controllable, but rather dependent upon the solvent and temperature treated. By considering the difference in pressure between these two systems, the yield difference is not significant because higher pressure results in higher yield. Just for comparison, the yield of FAME from oleic acid treated with supercritical dimethyl carbonate at $300{ }^{\circ} \mathrm{C}$ and $9 \mathrm{MPa}$ is shown in Fig. 3. At the lower temperature $\left(300{ }^{\circ} \mathrm{C}\right)$ and lower pressure $(9$ MPa) studied, the achieved yield was high enough, and comparable to the above two systems at $350^{\circ} \mathrm{C}$ treatment. 
These results are significant enough when compared to previous results. Fabbri et al. (2007) reported $5 \mathrm{~h}$ of reaction with $\mathrm{MeO}-\mathrm{Na}$ as a catalyst in reacting dimethyl carbonate with soybean oil to produce biodiesel, while Diasakou et al. (1998) reported that, without a catalyst, methyl esterification of soybean oil required 10 h to get $85 \%$ yield at $235{ }^{\circ} \mathrm{C}$. Furthermore, Marinkovic and Tomasevic (1998) reported to need $3 \mathrm{~h}$ reaction, with acid catalyst, to obtain a similar result.

By comparing the result in this study with these previous works, the non-catalytic supercritical process utilizing dimethyl carbonate was significant in biodiesel production. Thus, dimethyl carbonate is highly potential as a reactant for a supercritical method for biodiesel production.

\subsection{Potential of dimethyl carbonate as a reactant for biodiesel production}

The search for an alternative fuel fully derivable from renewable resources in an ongoing process is necessary as the fatty acid methyl esters produced from fossil-based methanol as a reactant is not yet a genuine biodiesel. Therefore, it is of great interest from a practical point of view to study a possible process using potential reactants rather than methanol under non-catalytic supercritical condition.

In this study, dimethyl carbonate was selected as a reactant for exploring a new non-catalytic process for supercritical biodiesel production. The raw materials for dimethyl carbonate production could possibly be derived from syngas, obtained by potential route of thermochemical conversion from biomass and, therefore, the resultant biodiesel would potentially qualified as a genuinely environmentally friendly biofuel. In 
addition, the process being reported in this study is a non-catalytic process which reduces the purification requirement and increases the yield.

The schematic of this new process is generalized and shown in Fig. 4 for oil containing some free fatty acids. As this process is a catalyst-free process, only removal of dimethyl carbonate and citramalic acid with glyoxal, possibly in a form of glycolic acid (Kiyoura and Kogure, 1997) from the lower part is required and complicated posttreatment process is not necessary. These organic acids produced may be expected to serve together as acid catalysts in the reaction system.

More interesting in this study was that, glycerol carbonate was produced as one of the intermediates, detected in the remaining lower portion as depicted in Fig. 2. This component of stable, colorless liquid possesses higher economic value than the abundantly available glycerol (Rokicki et al., 2005). Glycerol carbonate and its derivatives reported in several studies could offer useful applications such as solvent for several types of materials including paint, dyes and adhesives and as a new source of new polymeric materials (Cheol et al., 2003, 2004). Glycerol carbonate could also be a part of cosmetic or dermatological composition useful as inhibitors of bacteria and fungi (Roelf et al., 2000) and emulsifier (Joerg et al., 1999).

In addition, citramalic acid was found to exist together with glycerol carbonate in the lower portion after the supercritical dimethyl carbonate treatment as shown in Fig. 2. If separation is possible, citramalic acid, in high purity, is a novel compound with high value in pharmaceutical applications (Ruey and Eugen, 1997). Furthermore, glyoxal as a result of the fatty acid treated with supercritical dimethyl carbonate may exist in a form of glycolic acid due to the high temperature and pressure condition in the reaction. This 
glycolic acid could possibly give an acidic catalytic effect in the reaction. Glycolic acid or hydroxyacetic acid is used widely in printing, textile dyeing and rust and scale removal (Kiyoura and Kogure, 1997).

\section{Conclusions}

The potential of dimethyl carbonate as a reactant in supercritical biodiesel production was investigated. The results presented in this study proved that triglycerides could be converted into fatty acid methyl esters by reacting it with dimethyl carbonate in a non-catalytic supercritical process. Fatty acids were also converted completely to their corresponding fatty acid methyl esters in the supercritical dimethyl carbonate process.

Although further experiments are required to assess the remnants of glycerol carbonate, citramalic acid and glyoxal as by-products, this study has fulfilled its aim in providing a preliminary report on determining a potential reactant in non-catalytic supercritical process to produce biodiesel by utilizing dimethyl carbonate. This could charter the path to greener ways and a new non-catalytic process in producing biodiesel fuel via supercritical process. 


\section{References}

Cheol, J.S., Hyeok, K.C., Mun, K.J., 2004. Thermosetting resin composition and paint automobile. Republic of Korea patent 2003-0059847.

Cheol, J.S., Seok, J.Y., Hyeok, K.C., Jin, K.D., 2003. Paint composition for top coat of composition. Republic of Korea patent 2004-0070942.

Diasakou, M., Louloudi, A., Papayannakos, N., 1998. Kinetics of the non-catalytic transesterification of soybean oil. Fuel 77, 1297-1302.

Fabbri, D., Bevoni, V., Notari, M., Rivetti, F., 2007. Properties of a potential biofuel obtained from soybean oil by transmethylation with dimethyl carbonate. Fuel 86, 690-697.

Imahara, H., Minami, E., Hari, S., Saka, S., 2008. Thermal stability of biodiesel in supercritical methanol. Fuel 87, 1-6.

Isayama, Y., Saka, S., 2007. Catalyst-free biodiesel production with supercritical carboxylate esters as a substitute for methanol. In: Abstracts of the 16th Annual Meeting of the Japan Institute of Energy, pp. 238-239 (in Japanese).

Joerg, K., Thorsten, L., Holger, T., Hermann, H., 1999. Surface-active compositions, especially cosmetics, containing glycerol carbonate as emulsifier. Germany patent 1999-19756454.

Kiyoura, T., Kogure, Y., 1997. Synthesis of hydroxyacetic acid and its esters from glyoxal catalyzed by multivalent metal ions. App. Catal. A:General 156, 97-104.

Kusdiana, D., Saka, S., 2004. Two-step preparation for catalyst-free biodiesel fuel production. Appl. Biochem. Biotechnol. 115, 781-791. 
Marinkovic, S.S.S., Tomasevic, A.V., 1998. Transesterification of sunflower oil in situ. Fuel 77, 1389-1391.

Mittelbach, M., Remschmidt, C., 2004. Biodiesel. Boersedruck Ges.m.b.H, Vienna.

OECD SIDS, Organisation for Economic Co-operation and Development and Development Screening Information Data Sets., 2000. Glyoxal. In: United Nations Envi. Prog. Publication. pp. 124-178.

Rokicki, G., Rakoczy, P., Parzuchowski, P., Sobiecki, M., 2005. Hyperbranched aliphatic polyethers obtained from environmentally benign monomer: glycerol carbonate. Green Chem. 7, 529-539.

Rolf, W., Sabine, K., Joerg, K., Holger, T., 2000. Deodorizing cosmetic agents. Germany patent 2000-19858812.

Ruey, J.Y., Eugen, J.V.S., 1997. Method of using citramalic acid for treating wrinkles. United States patent-5660440.

Saka, S., Kusdiana, D., 2001. Biodiesel fuel from rapeseed oil as prepared in supercritical methanol. Fuel 80, 225-231.

Sheehan, J., Cambreco, V., Duffield, J., Garboski, M., Shapouri, H., 1998. An overview of biodiesel and petroleum diesel life cycles. In: A report by US Department of Agriculture and Energy, pp. 1-35.

Tomasevic, A.V., Marinkovic, S.S.S., 2003. Methanolysis of used frying oil. Fuel Process. Technol. 81, 1-6.

Tundo, P., 2001. New developments in dimethyl carbonate chemistry. Pure Appl. Chem. 73, 1117-1124. 
Tundo, P., Selva, M., 2002. The chemistry of dimethyl carbonate. Acc. Chem. Res. 35, 706-716.

Wang, M., Wang, H., Zhao, N., Wei, W., Sun, Y., 2006. Synthesis of dimethyl carbonate from urea and methanol over solid base catalysts. Catal. Comm. 7, 6-10.

Warabi, Y. Kusdiana, D., Saka, S., 2004. Reactivity of triglycerides and fatty acids of rapeseed oil in supercritical alcohols. Bioresour. Technol. 91, 283-287. 


\section{Figure Captions}

Fig. 1. GPC chromatograms of the upper portion as rapeseed oil was treated by supercritical dimethyl carbonate at $350{ }^{\circ} \mathrm{C} / 20 \mathrm{MPa}$ for various reaction times.

Fig. 2. GPC chromatograms of the lower portion as rapeseed oil was treated by supercritical dimethyl carbonate at $350{ }^{\circ} \mathrm{C} / 20 \mathrm{MPa}$. The aunthentic standard peaks of glycerol carbonate and citramalic acid are shown for comparison.

Fig. 3. Yield of fatty acid methyl ester (FAME) from rapeseed oil and oleic acid as treated with supercritical dimethyl carbonate at $350{ }^{\circ} \mathrm{C} / 20 \mathrm{MPa}$ and $300{ }^{\circ} \mathrm{C} / 9 \mathrm{MPa}$, respectively. For comparison, the yield of FAME from rapeseed oil as treated with supercritical methanol at $350{ }^{\circ} \mathrm{C} / 43 \mathrm{MPa}$ is included.

Fig. 4 Schematic process of biodiesel production from oil with some free fatty acids by supercritical dimethyl carbonate. 


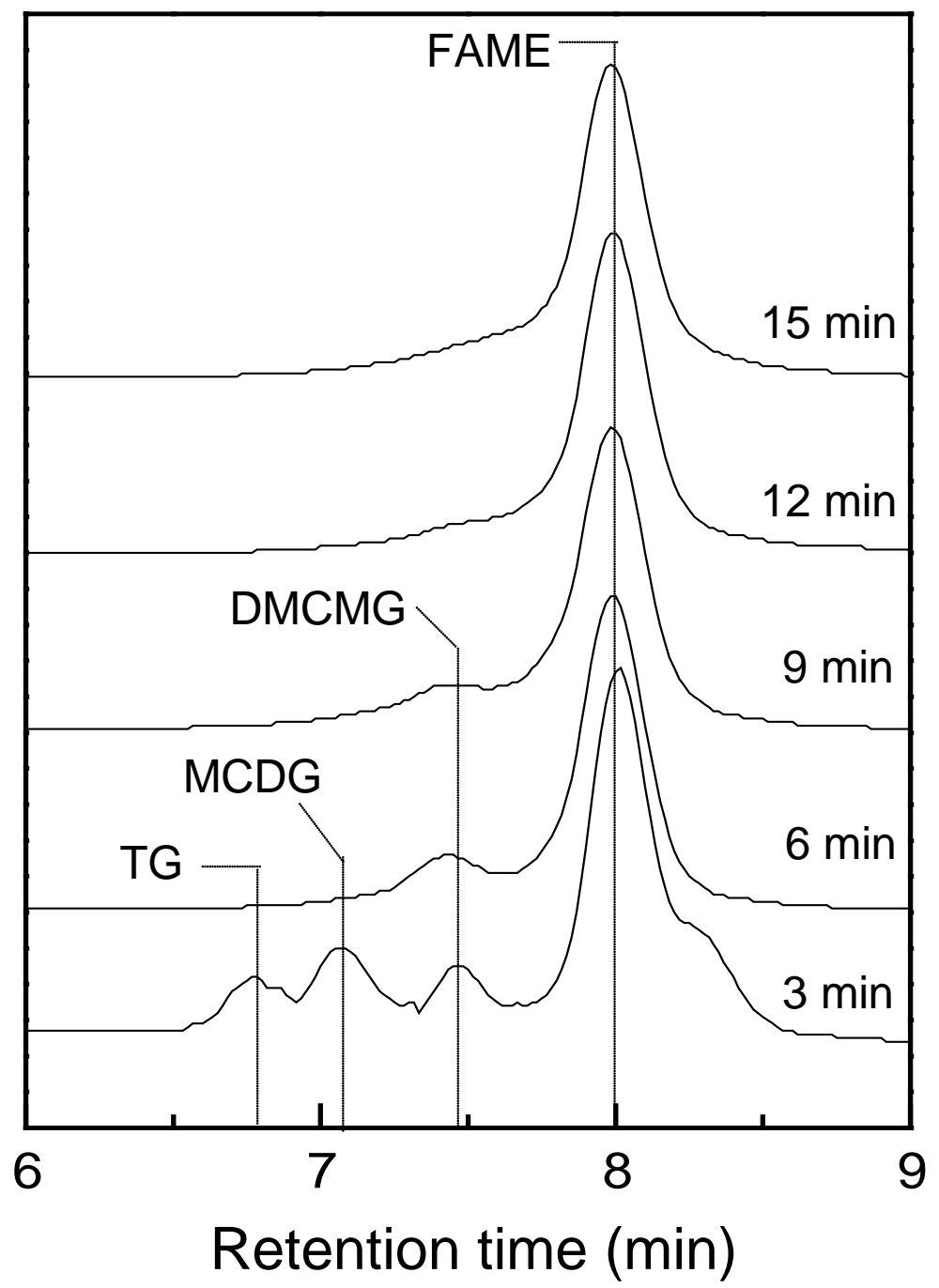

Fig. 1. GPC chromatograms of the upper portion as rapeseed oil was treated by supercritical dimethyl carbonate at $350{ }^{\circ} \mathrm{C} / 20 \mathrm{MPa}$ for various reaction times. 


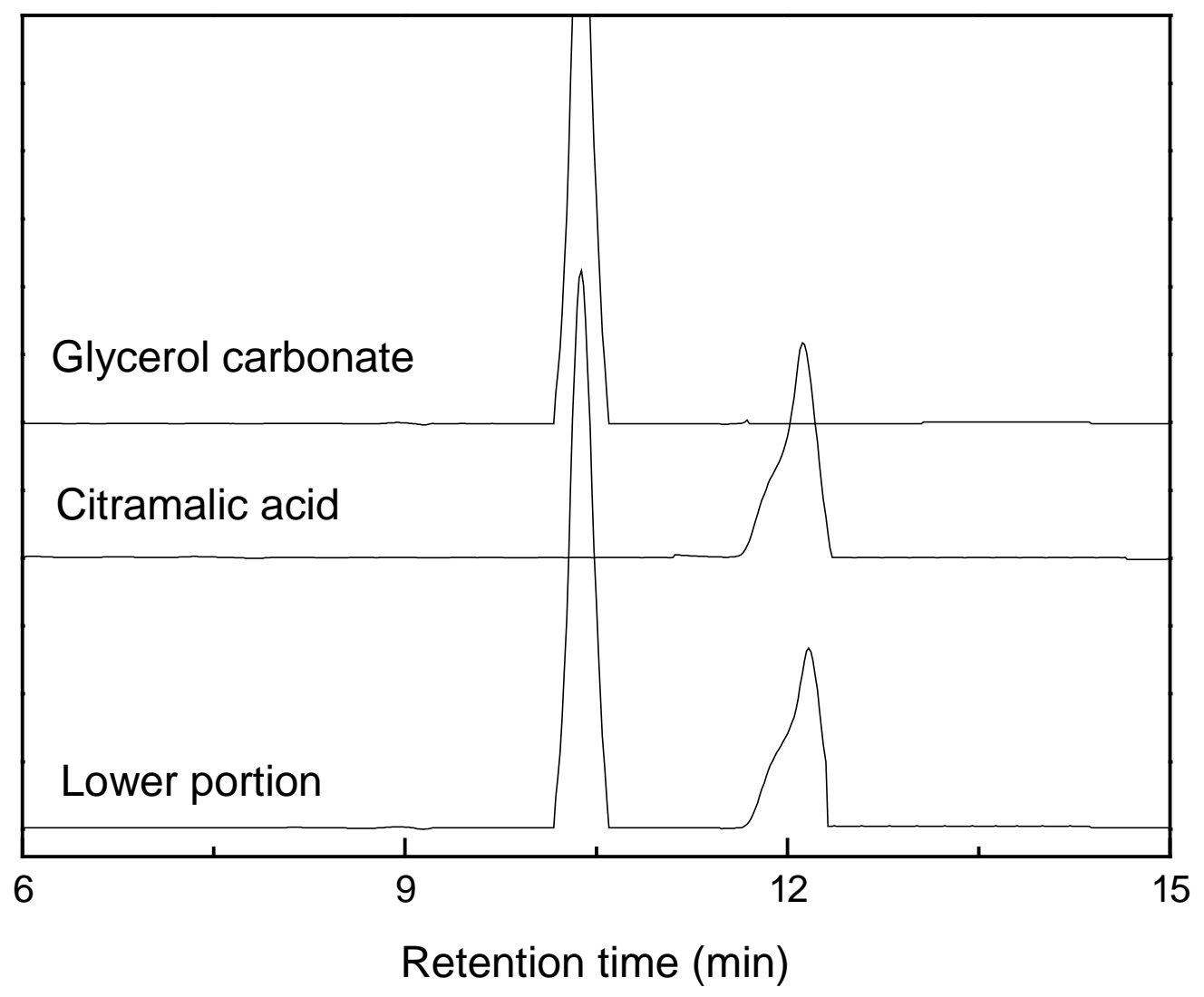

Fig. 2. GPC chromatograms of the lower portion as rapeseed oil was treated by supercritical dimethyl carbonate at $350{ }^{\circ} \mathrm{C} / 20 \mathrm{MPa}$. The aunthentic standard peaks of glycerol carbonate and citramalic acid are shown for comparison. 


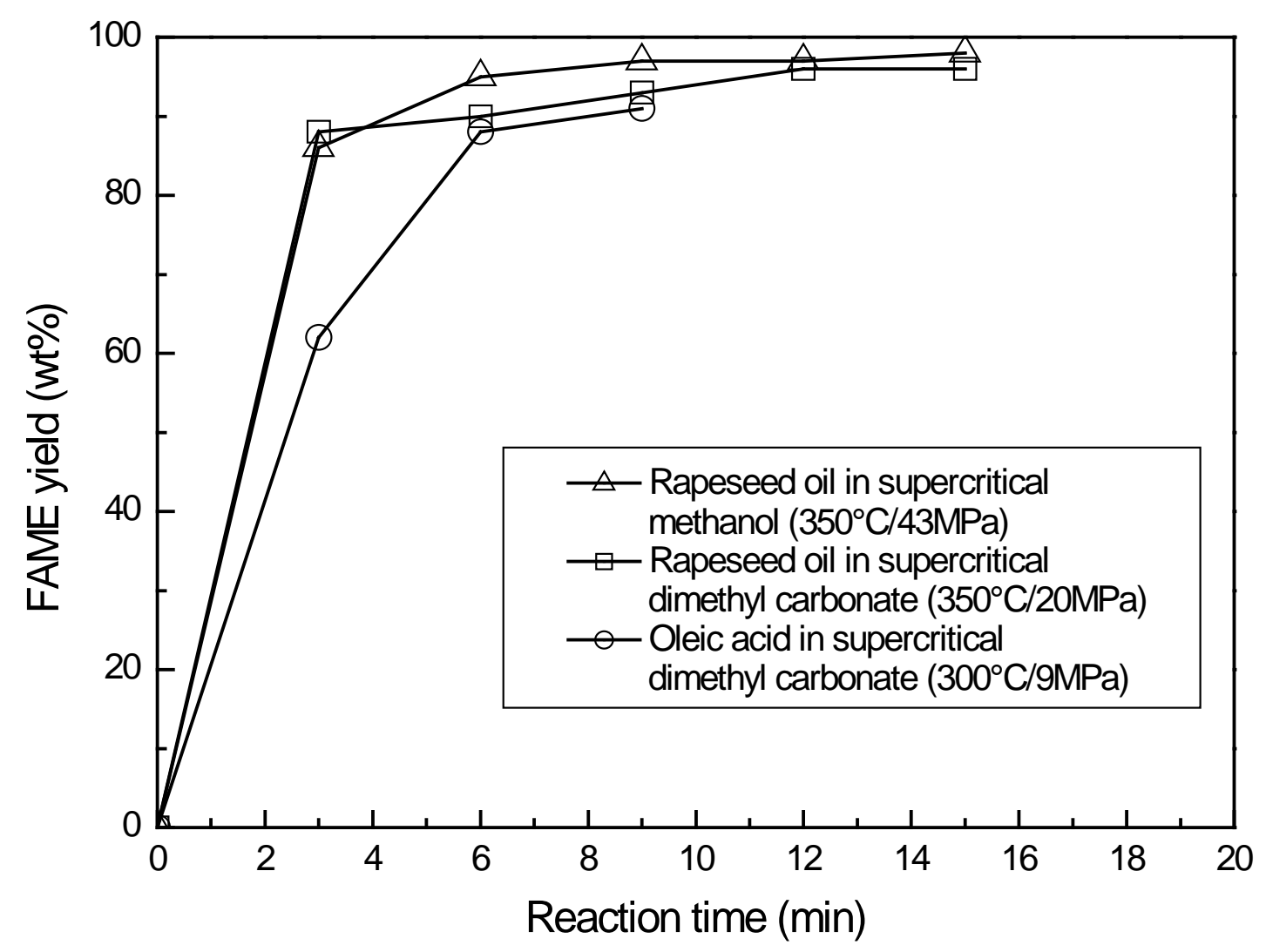

Fig. 3. Yield of fatty acid methyl ester (FAME) from rapeseed oil and oleic acid as treated with supercritical dimethyl carbonate at $350{ }^{\circ} \mathrm{C} / 20 \mathrm{MPa}$ and $300{ }^{\circ} \mathrm{C} / 9 \mathrm{MPa}$, respectively. For comparison, the yield of FAME from rapeseed oil as treated with supercritical methanol at $350{ }^{\circ} \mathrm{C} / 43 \mathrm{MPa}$ is included. 


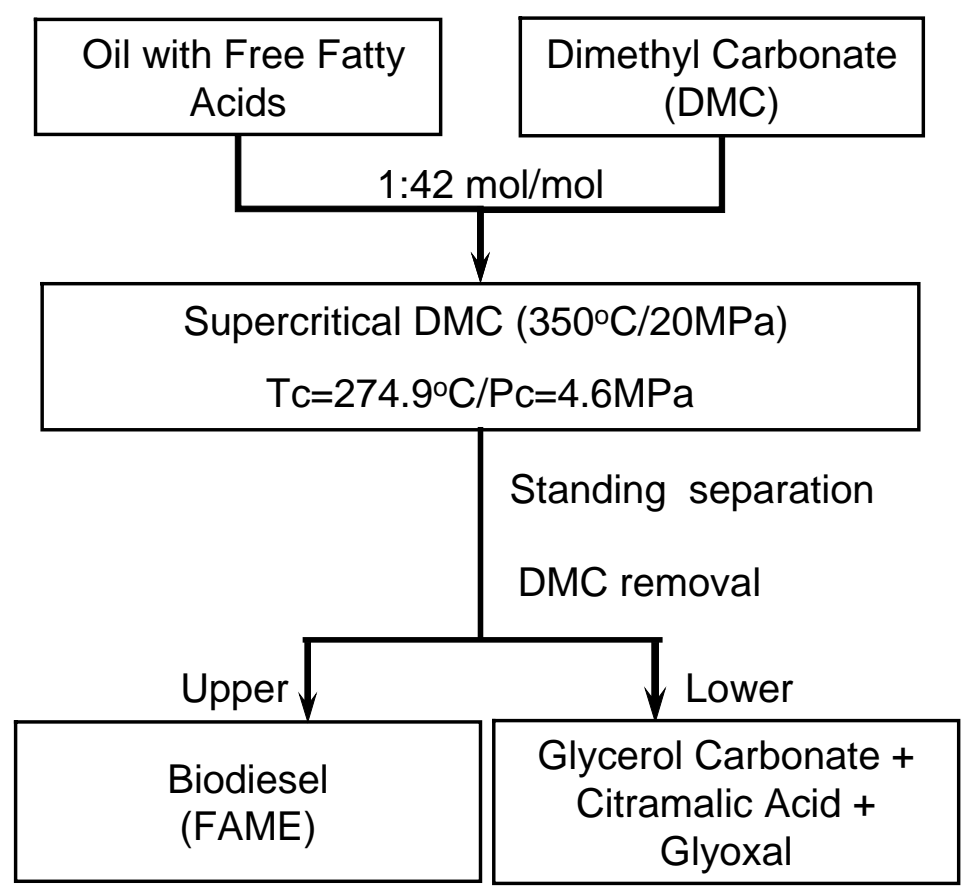

Fig. 4 Schematic process of biodiesel production from oil with some free fatty acids by supercritical dimethyl carbonate. 
Table 1

Physical and thermodynamic properties of dimethyl carbonate ${ }^{\mathrm{a}}$

\begin{tabular}{lc}
\hline Properties & Values \\
\hline Pc, critical pressure $(\mathrm{MPa})$ & 4.63 \\
Tc, critical temperature $\left({ }^{\circ} \mathrm{C}\right)$ & 274.9 \\
Tm, melting temperature $\left({ }^{\circ} \mathrm{C}\right)$ & 4.6 \\
Tb, boiling temperature $\left({ }^{\circ} \mathrm{C}\right)$ & 90.3 \\
density at $20^{\circ} \mathrm{C}(\mathrm{g} / \mathrm{ml})$ & 1.07 \\
viscosity at $20^{\circ} \mathrm{C}(\mathrm{cps})$ & 0.625 \\
flashing point $\left({ }^{\circ} \mathrm{C}\right)$ & 18.0 \\
dielectric constant & 3.09 \\
dipole moment $(\mu, \mathrm{D})$ & 0.91 \\
$\Delta H$ vap $(\mathrm{kcal} / \mathrm{kg})$ & 88.2 \\
solubility $\mathrm{H}_{2} \mathrm{O}(\mathrm{g} / 100 \mathrm{~g})$ & 13.9 \\
\hline
\end{tabular}

${ }^{\mathrm{a}}$ Tundo, 2001. 